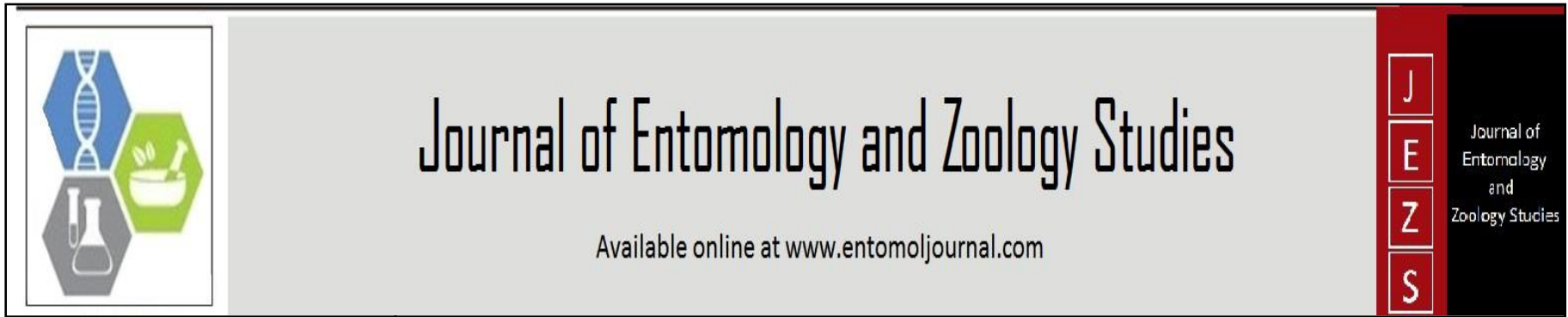

E-ISSN: 2320-7078

P-ISSN: 2349-6800

www.entomoljournal.com

JEZS 2020; 8(6): 502-508

(C) $2020 \mathrm{JEZS}$

Received: 24-08-2020

Accepted: 22-10-2020

\section{R Gopalakrishnan}

Division of Entomology, ICAR-

Indian Agricultural Research

Institute, New Delhi, India

\section{S Subramanian}

Division of Entomology, ICARIndian Agricultural Research

Institute, New Delhi, India

\section{Vinay Kalia}

Division of Entomology, ICARIndian Agricultural Research Institute, New Delhi, India
Corresponding Author: R Gopalakrishnan

Division of Entomology, ICAR-

Indian Agricultural Research

Institute, New Delhi, India

\section{RNAi machinery in insects and its challenges in pest management: A review}

\author{
R Gopalakrishnan, S Subramanian and Vinay Kalia
}

DOI: $\underline{\text { https://doi.org/10.22271/j.ento.2020.v8.i6g.7901 }}$

\section{Abstract}

RNA interference (RNAi) is a gene silencing mechanism mediated by double-stranded RNA (dsRNA) through post-transcriptional regulation. RNAi is capitalized for studying gene function in a variety of organisms and it is commonly employed for down regulating gene expression in cell. The principle of RNAi silencing involves custom steps such as processing of dsRNA, formation of RNA-induced silencing complex (RISC), target mRNA binding and cleavage. Nucleolytic degradation of the besieged mRNA by the RNase I enzyme (Argonaute - in case of insects) and RNase $\mathrm{H}$ enzyme (slicer - in case of nematode) results in gene silencing. The dsRNA uptake mechanism is mediated either through transmembrane channel or through endocytosis in insects. Among them SID-1 protein with 4 transmembrane domains is the major portal site for dsRNA uptake in insect midgut [15]. RNAi was successfully established in several insect orders like Coleoptera, Orthoptera, Diptera, Hemiptera and Lepidopteran pests such as corn planthopper, whitefly and pea aphid ${ }^{[51]}$. RNAi was highly efficient in coleopteran insects and have very low efficient in lepidopteran insects and the range of efficiency varies from $40 \%$ to $90 \%$ in insects. The variation is due to the inherent difference in RNAi machinery in insects influenced by different factors such as RNase, RNA-dependent polymerase (RdRP), SID 1 transmembrane channels and gut $\mathrm{pH}^{[32]}$. The presence of RNA nuclease (RNase) in the midgut and absence of RdRP in insects results in degradation of dsRNA in insect and trapping of dsRNA in acidic bodies in the midgut cells yields poor RNAi response in lepidopteran insects ${ }^{[45]}$. Understanding the inherent difference in RNAi machinery will help to resolve the strategies for efficient pest management through RNAi.

\section{Keywords: RNAi, insects, SID 1, insensitivity}

\section{Introduction}

Plants had originated above 700 million years ago and insects had originated 500 million years ago. Both insects and plants are in co-evolution for millions of years and insects started using plants as a source of food, shelter and reproduction. The natural enemies such as predators and parasitoids play a major role in diminishing the insect pest population in ecosystem. Apart from natural control, human intervention also aims at reducing the population level of insect pests and evolution of technology had resulted in modern means of pest management tools like biopesticides, insecticides with novel mode of action, microbial pesticides and biotechnological approaches like RNA interference etc.

\subsection{RNA Interference}

RNAi is a conserved process occurring naturally in all organism for gene regulation and defense against pathogens. The major principle of RNAi is post-transcriptional sequence specific gene silencing induced through double stranded RNA (dsRNA) ${ }^{[61]}$. RNAi can be divided into three pathways based on the small RNA biogenesis and the Argonaute protein: microRNA (miRNA), small interfering RNA (siRNA) and piwi-interacting RNA pathways. Among them, the siRNA pathway is the most prospective tool in insect pest control. The efficacy of RNAi varies among different insect orders and also depends upon various factors, including the target gene selection, method of dsRNase delivery, and expression of dsRNAs and presence of off-target effects. RNAi-mediated silencing of different insect genes involved in various physiological processes was found tobe detrimental to insect growth, development and survival RNA interference (RNAi), usually referring to the small interfering (si) RNA pathway ${ }^{[56]}$. 


\subsection{History of RNAi}

RNAi, the post-transcriptional gene silencing is known as cosuppression in Petunia plant and quelling in Neurospora fungi. In 1990, Napoli and Jorgensen defined RNAiphenomenon in Petunia plant and called it as "cosuppression". There experiment was based on Chalcone synthase (CHS), a key enzyme for flavonoid biosynthesis in plants. It is the rate-limiting enzyme in anthocyanin biosynthesis resulting purple coloration in petals. The experiment was done to increase the expression of CHS enzyme but the result was massive reduction in expression of chalcone synthase gene in flowers producing white colour petals. Later on in 1992 Carlo Cogoni and Guiseppe Macino identified RNAi mechanism in fungus Neurospora crassa. They introduced a gene (al-1 gene), a carotenoid synthesis gene in the fungus but instead of over expression, radical inactivation of the mold's own gene was noticed. They called this gene inactivation in fungus as "quelling". In 1995, GuoS and Kemphues KJ were the first to put forth that sense RNA and antisense RNA were able to suppress the gene expression in worm in Caenorhabditis elegans. Later on in 1998, it was Andrew Fire and Craig Mello reported that it was dsRNA was most effective in RNAi than sense RNA by injecting dsRNA into $C$. elegans. They described this sequence-specific silencing and coined the term "RNA Interference “. In 2006 Andrew Fire and Craig Mello were awarded with Noble Prize in Physiology or Medicine for discovering RNAi mechanism $[1,39]$.

\section{Overview of RNAi in insects}

RNAi includes three major pathways lie small interference (siRNA), micro RNA (miRNA) and Piwi-interacting RNA (piRNA) pathway. RNAi pathway is centered in two major steps, initially dsRNA or microRNA is processed into a siRNA by the RNaseIII enzymes Dicer and Drosha. Later on siRNAs are complexed into the RNA-induced silencing complex (RISC). The siRNA is unwound in a strand specific manner during RISC assembly and this single-stranded siRNA locates target mRNA. Gene silencing is a result of the nucleolytic degradation of the targeted mRNA by the RNase $\mathrm{H}$ enzyme (slicer - in case of nematode) and RNase I enzyme (Argonaute - in case of insects). While in case of microRNAs the gene silencing is a result of translational inhibition due to mismatch of duplex ${ }^{[21]}$. The major aspects of RNAi in insects were

i. RNAi (siRNA) is one of the fundamental antiviral pathways in insects. Insects mostly lack an adaptive immunity system, which results in well-defined immunity network in insects ${ }^{[14]}$.

ii. Viral infection is the core reason for induction of RNAi pathway, which results in imbalance in homeostasis of the organism ${ }^{[36,43]}$.

iii. RNAi depends on the silencing of vital genes for survival in the target insect pest thus resulting in mortality or inhibition of the pest populations ${ }^{[37]}$.

iv. Gene silencing efficiency is decreased by nuclease activity of dsRNA in the insect gut as well as in the hemolymph ${ }^{[16]}$.

v. RNAi activity is also inhibited by another RNAi factor called virus-encoded suppressors

2.1 Major component for siRNA, miRNA and shRNA
generation
1. Drosha

2. Dicer

3. RNA-Induced Silencing Complex (RISC)

4. RNA-Dependent RNA Polymerase (RdRP)

5. Argonaute (Ago)

\subsubsection{Drosha}

Drosha main function is to processes the pri-miRNA into premiRNA in miRNA pathway, leaving 3' overhangs on premiRNA. The processing of drosha needs co-factor Pasha ${ }^{[24]}$.

\subsubsection{Dicer}

Dicer is an RNAse III like dsRNA specific ribonuclease (digest dsRNA into uniformly sized small RNAs (si RNA) present in RNAi mechanism in insects and plants. Usually the dsRNA should be with 25 nucleotides in length, complementary to target mRNAs for successful completion of target. Dicer belongs to ATP- dependent nucleases type of proteins. Dicer homologs are found in

C. elegans, Drosophila, yeast and humans.

\subsubsection{RNA-Induced Silencing Complex (RISC)}

RISC complex is the core processing factor in RNAi mechanism in insects and plants. It is a nuclease complex made up of different proteins and siRNA complex. It specifically targets the target nucleotide and destroys endogenous mRNAs complementary to the siRNA present in its complex ${ }^{[24]}$.

\subsubsection{Argonaute (Ago)}

Argonaute is a "homology seeking" protein complex which helps in specific binding to target mRNA and it is the part of RISC complex in siRNA, miRNA and shRNA pathways. Argonaute family members reported in insects includes AGO1, AGO2, Piwi, and Sting ${ }^{[38]}$.

\subsubsection{Difference between miRNA and siRNA}

The siRNA originates with dsRNA and it progress as a response to entry of foreign RNA in to the system (usually viral). It is mostly 100 percent complementary to the target mRNA. While miRNA originates with ssRNA (hairpin secondary structure) and it helps in the regulation of posttranscriptional gene expression. The miRNA is not 100 percent complementary to the target and plays a major role in regulation of gene expression ${ }^{[12]}$.

\section{Mechanism of RNA interference}

The first phase of RNAi is production of dsRNA either in plant system or in incorporation into the insect body. The ingested dsRNA on reaching the insect midgut it selectively binds to the receptors in the midgut (Transmembrane SID like receptors). This binding leads production of charge in the receptor which results in changing of the configuration of the SID domain. This change in configuration creates a pore in the receptor through which the dsRNA will enter the midgut and reaches the midgut cells. In the midgut cells actual the dsRNA is acted upon by dicer enzyme and cleaved into small siRNAs. The siRNAs then go and binds with aragonite protein complex to form RISC complex, which cleaves them on targeted binding to target mRNA ${ }^{[18]}$.

The RNAi response in insect can be classified in to two lie cell-autonomous and non-cell-autonomous response. In cellautonomous type the silencing process is only limited to the cell where the dsRNA is introduced and encompasses the RNAi process within individual cells. In non-cell-autonomous 
type the silencing process take place in the whole tissues/cells different from the location of application or production of the dsRNA. Further the non-cell-autonomous type can be grouped into environmental RNAi and systemic RNAi. If the dsRNA is up taken from outside the insect body from environment or surrounding and RNAi induced in non-systemic manner it is called environmental RNAi, while if the RNAi response is induced by injection of dsRNA in a systemic manner in insect body is called systemic RNAi ${ }^{[11,53,56]}$.

Potential RNAi target genes in major insect pest

\begin{tabular}{|c|c|c|c|}
\hline Insect Species & Target Gene & Delivery method & Reference \\
\hline \multicolumn{4}{|c|}{ Coleoptera } \\
\hline Diabrotica undecimpunctata & V-ATPase A; V-ATPase E & Feeding & (Baum et al., 2007) \\
\hline Leptinotarsa decemlineata & b-actin; protein transport protein sec 23 & Feeding & (Zhu et al., 2011) \\
\hline Tribolium castaneum & Chitin synthase genes $T c C H T-A$ & Injection & (Arakane et al., 2008) \\
\hline \multicolumn{4}{|c|}{ Diptera } \\
\hline Bactrocera dorsalis & Fatty acid elongase Noa; GTPase Rabl1 & Feeding or injection & (Li et al., 2011) \\
\hline \multicolumn{4}{|c|}{ Lepidoptera } \\
\hline Helicoverpa armigera & Acetylcholinesterase gene $A C h E$ & Feeding & (Kumar et al., 2009) \\
\hline Plutella xylostella & Cytochrome P450 CYP6BG1 & Feeding & (Bautista et al., 2009) \\
\hline Spodoptera litura & Vitellogenin receptor $S N g R$ & Injection & (Shu et al., 2011) \\
\hline \multicolumn{4}{|c|}{ Hemiptera } \\
\hline Acyrthosiphon pisum & Gut digestive enzyme cathepsin- $L$ & Injection & (Mutti et al., 2006) \\
\hline Nilaparvata lugens & Glutathione-S-transferase gene $n$ lgst $1-1$ & Feeding & (Sun et al., 2013) \\
\hline \multicolumn{4}{|c|}{ Orthoptera } \\
\hline Schistocerca gregaria & Cytochrome P450 gene $\mathrm{CYP} 6 \mathrm{HI}$ & Injection & (Marchal et al., 2012) \\
\hline \multicolumn{4}{|c|}{ Blattaria } \\
\hline Blattella germanica & Hyper-trehalosemic hormone gene $H T H$ & Injection & (Huang and Lee, 2011) \\
\hline \multicolumn{4}{|c|}{ Acari } \\
\hline Tetranychus urticae & b subunit of co-atomer protein complex $T$-COPB2; & Feeding & (Kwon et al., 2013) \\
\hline
\end{tabular}

\section{Challenges in Applying RNAi for Pest Control}

The approach of RNAi in insect pest management was first commercialization in the western corn rootworm (Diabrotica virgifera virgifera) and while in case of other insects there are still in the lab stages and need further work for functional gene analysis ${ }^{[41,61]}$.

\section{Major challenges in RNAi are}

The major factors deterring the use of RNAi for successful insect pest management are ${ }^{[37]}$

1. dsRNA delivery in practice

2. Efficiency of RNAi in Pest Control

3. Resistance Development to RNAi

\section{1 dsRNA delivery in practice}

The dsRNA delivery system is the major factor which determines the success rate of RNAi across the different major orders of insects. Gene silencing is mostly limited to cells that uptake the target gene dsRNAs hence more the uptake of dsRNA into the cell the more is the success rate. The different types of delivery system used to transfer the dsRNA into insect

system are ${ }^{[61]}$

The main dsRNA delivery methods:

i. Soaking

ii. Feeding

iii. Injection and transgenic plants expressing dsRNA.

\subsubsection{Levels of dsRNA uptake in insects:}

1. dsRNA uptake from the environment into the insect body.

2. Cellular uptake and the stability of dsRNA in insects after uptake of the dsRNA from the environment into the insect body.

\subsection{2 dsRNA ingestion Methods}

1. Diet ingestion or direct uptake through insect exocuticle.
2. Transgenic plants express specific dsRNAs (eg. D. virgiferavirgifera)

3. Sprayable formations (Leptinotarsa decemlineata) ${ }^{[13]}$

\subsection{Efficiency of RNAi in Pest Control}

The major factors influencing the efficiency of RNAi are delivery method, the presence of key enzymes in midgut and gut $\mathrm{pH}$ of the targeted insect. Expression level of the target gene is higher in injection method of dsRNA delivery in to haemolymph than oral method ${ }^{[10]}$.

\subsection{Resistance Development to RNAi}

The first case offield resistance of RNAi was reported in resistant strains of $D$. virgifera against dsRNA (dsDvSnf7) which showed more than 130-fold resistance under field condition. In D. virgifera, DvSnf7 gene was targeted which encodes for protein ESCRT (Endosomal Sorting Complex Required for Transport) -III complex an important transmembrane protein sorting present in midgut cells ${ }^{[20]}$. The lower level of dsRNA content in resistant strain of the insect haemolymph makes them less vulnerable with susceptible type strain. This proves that resistant strain was able to reduce the uptake of dsRNA into midgut cells and the introduced dsRNAs were also degraded or sequestrated by special cells in the gut region of insect ${ }^{[20]}$.

\section{Possible causes for RNAi insensitivity in insects 5.1 Intrinsic of the species}

Several factors play a critical role in influencing the sensitivity of RNAi to insects were the efficiency of degradation of ingested alien dsRNAs, deficient amplification, spreading of the RNA signal with in the nearby neighboring tissues and low level of response of core RNAi genes after dsRNA treatment. In corn rootworm, Diabrotica virgifera, if the ingested dsRNAs is larger than $60 \mathrm{bp}$, the efficiency of RNAi was reported to attain maximum response. It was due to the fact that the extracellular domain of the SID- 
1 transmembrane protein selectively binds only to long dsRNAs than smaller ones ${ }^{[27,57] .}$

\subsection{RNAi mechanism in Nematode and Insect a comparison}

The efficiency of RNAi varies from order to order in insect and also with other organisms like nematode. It was found the variation in mechanism of RNAi was the major reason behind this scenario and it urges to study and explore the capricious mechanism of RNAi in different organism for effective application of RNAi over those organisms. In many insect species, the gene knockdown was found to be less than $60 \%$ and often the mechanism was temporary which in turn is influenced by many factors ${ }^{[25]}$.

There are two types of SID transmembrane protein in nematodes lie SID 1 and SID 2. The SID 1 is present in the outer membrane of midgut transferring the dsRNA from midgut lumen into the midgut cells, while the inner protein SID 2 helps in systematization of introduced dsRNA in the neighboring tissues enabling systemic effect in the nematode. While in case of insect only SID 1 protein is reported which may influence the efficiency of uptake of dsRNA in to the midgut

cells ${ }^{[31]}$.

\section{3 dsRNA translocation in insect midgut}

The translocation of dsRNA into insect midgut is mediated by several transmembrane proteins present in the midgut cells. The major one include SID 1 and SID 2 proteins of which Sid-1 proteins are reported to be present in most of the insect species and there is no report of presence of Sid2 proteins in insect species through genomes sequencing. In Drosophila it is reported that the uptake of dsRNA is mediated through endocytic pathway and Pattern recognition receptors (PRRs) receptors present in insect midgut. Apart from that several scavenger receptors were are also present in midgut cells and silencing them with RNAi diminished the uptake of dsRNA up to $90 \%$ in D. melanogaster ${ }^{[8,50]}$.

In case of Coleopteran insects both the Sid-1-like channel proteins and the receptor-mediated endocytosis plays a major role in dsRNA uptake, resulting in higher dsRNA uptake hence improved efficiency of RNAi in Coleoptera ${ }^{[7,40]}$. In $C$. elegans (as well as in plants and fungi) there is a peculiar protein enzyme complex called RdRP (ego-1 transcript) is present which is stated to amplifies the siRNAs after the cleavage of mRNA by RISC complex resulting in systemic pathway mechanism. Insects mostly lack these RdRP mutants in there RNAI mechanism making them insensitive to dsRNA (only SID 1 protein is present). In C. elegans both RRF-1 and EGO-1 were reported to be present and plays an essential role in secondary siRNA production from RNAi-targeted transcripts ${ }^{[49]}$.

\subsubsection{SID 1 receptor in midgut with SER protein complex in Insects}

The SID 1 receptor complex is the only means of transmembrane protein helpful to transfer dsRNA into the midgut cells. The SID 1 protein consists of 11 domains which are sandwiched in above the other forming a complex. At domain one there is a long loop consisting of several glycosylated sites and one $\mathrm{H}_{2} \mathrm{~N}$ element at tip giving stability to the SID 1 protein complex. There is also an inner loop present between domain 1 and 2 and between preceding domains which carry several $\mathrm{S}$ and $\mathrm{T}$ phosphorylated sites giving net positive charge to the SID 1 complex so that negatively charged dsRNA gets specifically attached to the protein. Once the dsRNA is attached to the domain an electric charge is produced which results in change in configuration of SID 1 complex leading to pore formation. Once the dsRNA has entered the complex the pore is than closed. The pore is of larger size so as to accommodate the larger sized dsRNA and the pore is created only after the binding of dsRNA in to the receptors present in SID 1 protein ${ }^{[48]}$.

\subsubsection{Intrinsic of the tissue}

The uptake of dsRNA into epithelial cells of the insect midgut brush border membrane is an important step in RNAi mechanism in insects. The inner layering of peri-microvillar membrane in Hemiptera and peritrophic membrane in Coleoptera and Lepidoptera species mid-gut acts as a mechanical barrier for delivery of dsRNA. The cellular uptake of dsRNA through endocytosis pathway is effective only if the entrapped dsRNA in endosomes are able to discharge or escape from the endosome and get transferred into the cytoplasm or else in results in reduced efficacy. Though the dsRNA is more stable than ssRNA they are quickly degradation the salivary nucleases in the insect midgut ${ }^{[55]}$. Several dsRNases are being reported in the saliva enzymes of Ligus lineolaris, which quickly digest the ingested dsRNA [2].

\subsubsection{Length and Concentration of dsRNA}

Length of dsRNA also affects the efficiency of RNAi mechanism. In insect species an optimum range of 140 to 500 nucleotides in length are required for effective binding silencing. Length of 60 and 30-bp of dsRNAs can induce 70 and $30 \%$ of gene knockdown in Tribolium,

respectively ${ }^{[33]}$. Multiple injection of different dsRNAs at a time leads to competition within them cellular uptake leading to oversaturation and results in poor RNAi response ${ }^{[19]}$.

\subsection{RNA interference in the termite Reticulitermes flavipes}

Termite is the major destructive pest in the world often attacking the whole plant system from root to top of the plant. The RNAi mechanism is almost success in case of termites due to their peculiar behavior of trophallaxis, which leads to rapid transfer of dsRNA throughout entire colonies in short periods of time ${ }^{[59]}$. Two genes were tested for RNAi in termites such as Hex 2 gene and larval cuticle protein gene, which showed increased levels of dsRNA among the individuals of termite colony due to the trophallaxis behavior.

\section{5 dsRNA degrading enzymes in gut of desert locust, Schistocerca gregaria}

The dsRNase is a $S g$-endoG transcript (four $\mathrm{Sg}$ dsRNase transcripts), an EndoG family which have potent dsRNA degrading capacity in midgut of desert locust. Bmalkaline nuclease is also expressed in the middle and posterior midgut, which are potent dsRNA degrading enzymes ${ }^{[4]}$.

\section{Barriers for successful RNAi in Lepidopteran}

The reduced efficiency of RNAi in Lepidopteran insects due to presence of alkaline $\mathrm{pH}$ in gut and presence of specific gene encoding for a nuclease that contributes to the RNAi insensitivity in this insect. The transcriptome analysis in Asian corn borer Ostrinia furnacalis revealed that "up56" gene is up-regulated in response to dsRNA, which codes for 
dsRNase enzyme. This nuclease has three-dimensional structure similarity to human exonuclease I. This protein is well-known as "RNAi Efficiency-related nuclease (REase). Presence of double-stranded ribonucleases (dsRNase) in the lumen and hemolymph is the main reason for variability in the uptake and transport of dsRNA into and within the cells [16, 46, ${ }^{52]}$. The list of dsRNase present in several insect groups have been given below

The list of dsRNase present in several insect groups have been given below

\begin{tabular}{|c|c|}
\hline Insect Species & Reference \\
\hline Silkmoth, Bombyx mori & (Arimatsu et al., 2007) \\
\hline Migratory locust, Locusta migratoria & (Luo et al., 2013) \\
\hline Desert locust, Schistocerca gregaria & (Wynant et al., 2014) \\
\hline Pea aphid, Acyrthosiphon pisum & (Christiaens et al., 2014) \\
\hline Tarnished plant bug, Lygus lineolarus & (Allen and Walker, 2012) \\
\hline
\end{tabular}

\section{1 dsRNase (Bm-dsRNase) in silkworm, Bombyx mori}

The presence of dsRNase is also reported in the midgut of silkworm, Bombyx mori, resulting in reduced uptake of dsRNA into system due to lower level of dsRNA in in midgut after enzymatic lysis by Bm-dsRNase. The Bm-dsRNase is concerned only in the midgut cells of silkworm and its concentration varies with in the mid gut region.

\subsection{Reduced stability and intracellular transport of dsRNA in insects}

Coleopterans insects mostly have systemic RNAi response due to presence of several transmembrane proteins to uptake the dsRNA while in case of lepidopteran insects it is nonsystemic and less efficient due to presence of fewer proteins, entrapment of dsRNA in endosomes in midgut and gut $\mathrm{pH}$ which destabilizes the dsRNA in midgut. Though the dsRNA escapes the dsRNase digestion and enters lepidopteran cells it is not processed into small interference RNA (siRNA) in further progress ${ }^{[44]}$. Entrapment of dsRNAs in endosomes is an evolutionary selective advantage of sequestering exogenous dsRNA viruses in response of antiviral immune response system in insects ${ }^{[42]}$. Degradation of dsRNA and trapping of dsRNA in acidic bodies cell is the major reason behind poor RNAi response in lepidopteran insects ${ }^{[44]}$.

\section{Pyramiding RNAi with Bt to Counters Insect Resistance} Several report of resistance of $\mathrm{Bt}$ cotton have been arising, to solve this problem there comes the emergence of new concept called Gene Pyramiding. Cotton plant producing both Bt toxin CrylAc and dsRNA (JH acid methyl transferase) for Helicoverpa armigera was produced which reduce resistant development against $\mathrm{Bt}$ cotton due to combined effect ${ }^{[29,58]}$. Refuges (non-transgenic) crops in Bt cotton filed will delay the resistance development by 14 to 75 years in pyramided cotton than Bt cotton alone ${ }^{[29,35]}$.

\section{Conclusion}

RNAi is a potent pest management tool and there is a need for understanding the RNAi machinery in insects for successful insect pest management. RNAi was found to be efficient against Coleopteran while it was insensitive to other orders like Lepidoptera and Dipterans. The presence of Rnase, RdRp, SID 1 specificity, $\mathrm{pH}$ of insect midgut and storage dsRNA in endosomes affect the efficiency of RNAi in insects. The availability of transcriptomic sequences or genomic data from different species makes RNAi more achievable. The major disadvantage of RNAi in the agricultural system is the off-target gene silencing effect on non-target organisms. The combined strategy of gene pyramiding, RNAi and Bt plays a vital role in managing insect pest resistance development in future and pyramiding genes with different MOA against insects helps in efficient management of targets pest.

\section{Reference}

1. Agrawal N, Dasaradhi PVN, Mohmmed A, Malhotra P, Bhatnagar RK, Mukherjee SK. RNA interference: biology, mechanism, and applications. Microbiol. Mol. Biol. Rev 2003;67(4):657-685.

2. Allen ML, Walker III WB. Saliva of Lygus lineolaris digests double stranded ribonucleic acids. Journal of Insect Physiology 2012;58(3):391-396.

3. Arakane Y, Specht CA, Kramer KJ, Muthukrishnan S, Beeman RW. Chitin synthases are required for survival, fecundity and egg hatch in the red flour beetle, Tribolium castaneum. Insect Biochemistry and Molecular Biology 2008;38:959-62.

4. Arimatsu Y, Furuno T, Sugimura Y, Togoh M, Ishihara $\mathrm{R}$, Tokizane $\mathrm{M}$ et al. Purification and properties of double-stranded RNA-degrading nuclease, dsRNase, from the digestive juice of the silkworm, Bombyx mori. Journal of Insect Biotechnology and Sericology 2007; 76(1):157-62

5. Baum JA, Bogaert T, Clinton W, Heck GR, Feldmann P, Ilagan $\mathrm{O}$ et al. Control of coleopteran insect pests through RNA interference. Nature Biotechnology 2007;25(11):1322.

6. Bautista MA, Miyata T, Miura K, Tanaka T. RNA interference-mediated knockdown of a cytochrome P450, CYP6BG1, from the diamondback moth, Plutella xylostella, reduces larval resistance to permethrin. Insect Biochemistry and Molecular Biology 2009;39:38-46.

7. Cappell SD, Chung M, Jaimovich A, Spencer SL, Meyer T. Irreversible APCCdh1 inactivation underlies the point of no return for cell-cycle entry. Cell 2016;166:167-80.

8. Chen J, Zhang D, Yao Q, Zhang J, Dong X, Tian H et al. Feeding-based RNA interference of a trehalose phosphate synthase gene in the brown planthopper, Nilaparvata lugens. Insect Molecular Biology 2010;19(6):777-786.

9. Christiaens O, Swevers L, Smagghe G. DsRNA degradation in the pea aphid (Acyrthosiphon pisum) associated with lack of response in RNAi feeding and injection assay. Peptides 2014;53:307-314.

10. Christiaens O, Tardajos MG, Martinez Reyna ZL, Dash M, Dubruel P, Smagghe G. Increased RNAi efficacy in Spodoptera exigua via the formulation of dsRNA with guanylated polymers. Frontiers in Physiology 2018;9:316.

11. Cooper AM, Silver K, Zhang J, Park Y, Zhu KY. Molecular mechanisms influencing efficiency of RNA interference in insects. Pest Management Science 2019;75(1):18-28.

12. Ekwall K. The RITS complex - a direct link between small RNA and heterochromatin. Molecular Cell 2004;13:304-5.

13. Fishilevich E, Vélez AM, Storer NP, Li H, Bowling AJ, Rangasamy $\mathrm{M}$ et al. RNAi as a management tool for the western corn rootworm, Diabrotica virgiferavirgifera. Pest Management Science 2016;72:1652-63.

14. Gammon DB, Mello CC. RNA interference-mediated antiviral defense in insects. Current Opinion in Insect 
Science 2015; 8:111-20.

15. Gu L, Knipple DC. Recent advances in RNA interference research in insects: implications for future insect pest management strategies. Crop Protection 2013;45:36-40.

16. Guan RB, Li HC, Fan YJ, Hu SR, Christiaens O, Smagghe $\mathrm{G}$ et al. A nuclease specific to lepidopteran insects suppresses RNAi. Journal of Biological Chemistry 2018;293(16):6011-6021.

17. Huang JH, Lee HJ. RNA interference unveils functions of the hyper-trehalosemic hormone on cyclic fluctuation of hemolymph trehalose and oviposition in the virgin female Blattella germanica. J Insect Physiol 2011;57:858-864.

18. Ivashuta $\mathrm{S}$, Zhang $\mathrm{Y}$, Wiggins BE, Ramaseshadri $\mathrm{P}$, Segers GC, Johnson S et al. Environmental RNAi in herbivorous insects. Rna 2015;21(5):840-850.

19. Joga MR, Zotti MJ, Smagghe G, Christiaens O. RNAi efficiency, systemic properties, and novel delivery methods for pest insect control: what we know so far. Frontiers in Physiology 2016;7:553.

20. Khajuria C, Ivashuta S, Wiggins E, Flagel L, Moar W, Pleau M et al. Development and characterization of the first dsRNA-resistant insect population from western corn rootworm, Diabrotica virgiferavirgifera LeConte. PloS One 2018;13(5):e0197059.

21. Kim Y, Tewari M, Pajerowski JD, Cai S, Sen S, Williams $\mathrm{J}$ et al. Polymersome delivery of siRNA and antisense oligonucleotides. Journal of Controlled Release 2009;134:132-40.

22. Kumar M, Gupta GP, Rajam MV. Silencing of acetylcholinesterase gene of Helicoverpa armigera by siRNA affects larval growth and its life cycle. J Insect Physiol 2009;55:273-278.

23. Kwon DH, Park JH, Lee SH. Screening of lethal genes for feeding RNAi by leaf disc-mediated systematic delivery of dsRNA in Tetranychus urticae. Pestic. Biochem Physiol 2013;75:105:69.

24. Lee SS, Lee RY, Fraser AG, Kamath RS, Ahringer J, Ruvkun G. A systematic RNAi screen identifies a critical role for mitochondria in $C$. elegans longevity. Nature Genetics 2003;33:40-8.

25. Li H, Jiang W, Zhang Z, Xing Y, Li F. Transcriptome analysis and screening for potential target genes for RNAi-mediated pest control of the beet armyworm, Spodoptera exigua. PLoS One 2013;8:e65931.

26. Li M, Ou X, Yang X, Guo D, Qian X, Xing L et al. Isolation of a novel C18- $\Delta 9$ polyunsaturated fatty acid specific elongase gene from DHA-producing Isochrysis galbana $\mathrm{H} 29$ and its use for the reconstitution of the alternative $\Delta 8$ pathway in Saccharomyces cerevisiae. Biotechnology Letters 2011;33:1823-30.

27. Li W, Koutmou KS, Leahy DJ, Li M. Systemic RNA Interference Deficiency-1 (SID-1) extracellular domain selectively binds long double-stranded RNA and is required for RNA transport by SID-1. Journal of Biological Chemistry 2015;290(31):18904-18913.

28. Luo Y, Wang X, Wang X, Yu D, Chen B, Kang L. Differential responses of migratory locusts to systemic RNA interference via double-stranded RNA injection and feeding. Insect Molecular Biology 2013; 22:574-83.

29. Ma W, Zhang T. Next-Generation Transgenic Cotton: Pyramiding RNAi with Bt Counters Insect Resistance. In Transgenic Cotton. Humana Press, New York, NY 2019, 245-256
30. Marchal E, Verlinden H, Badisco L, Van Wielendaele P, Broeck JV. RNAi-mediated knockdown of Shade negatively affects ecdysone-20-hydroxylation in the desert locust, Schistocerca gregaria. Journal of Insect Physiology 2012;58:890-6.

31. McEwan DL, Weisman AS, Hunter CP. Uptake of extracellular double-stranded RNA by SID-2. Molecular Cell 2012;47(5):746-754.

32. Meng F, Yang M, Li Y, Li T, Liu X, Wang G et al. Functional analysis of RNA interference related soybean pod borer (Lepidoptera) genes based on transcriptome sequences. Frontiers in Physiology 2018;9:383. doi: 0.3389/fphys.2018.00383.

33. Miller SC, Miyata K, Brown SJ, Tomoyasu Y. Dissecting systemic RNA interference in the red flour beetle Tribolium castaneum: parameters affecting the efficiency of RNAi. PloS One 2012; 7:e47431.

34. Mutti NS, Park Y, Reese JC, Reeck GR. RNAi knockdown of a salivary transcript leading to lethality in the pea aphid, Acyrthosiphon pisum. Journal of Insect Science 2006, 6.

35. Nandety RS, Kuo YW, Nouri S, Falk BW. Emerging strategies for RNA interference (RNAi) applications in insects. Bioengineered 2015;6(1):8-19.

36. Niu J, Meeus I, Cappelle K, Piot N, Smagghe G. The immune response of the small interfering RNA pathway in the defense against bee viruses. Current Opinion in Insect Science 2014;6:22-7.

37. Niu J, Taning CNT, Christiaens O, Smagghe G, Wang JJ. Rethink RNAi in Insect Pest Control: Challenges and Perspectives. In Crop Protection. 24-28 Oval Road, London NW1 7DX, England: Academic Press LtdElsevier Science ltd 2018;55:1-17

38. Novina CD, Sharp PA. The rnai revolution. Nature 2004;430:161-4.

39. Palli SR. RNA Interference: History, Mechanisms, and Applications in Pest Management. In Arthropod Diversity and Conservation in the Tropics and Subtropics. Springer, Singapore 2016, 397-413

40. Price DR, Gatehouse JA. RNAi-mediated crop protection against insects. Trends in Biotechnology 2008;26(7):393400.

41. Ramaseshadri P, Segers G, Flannagan R, Wiggins E, Clinton W, Ilagan $\mathrm{O}$ et al. Physiological and cellular responses caused by RNAi-mediated suppression of Snf7 orthologue in western corn rootworm (Diabrotica virgiferavirgifera) larvae. PloS One 2013;8(1):e54270.

42. Saleh MC, Tassetto M, Van Rij RP, Goic B, Gausson V, Berry B et al. Antiviral immunity in Drosophila requires systemic RNA interference spread. Nature 2009;458:34650 .

43. Schwenke RA, Lazzaro BP, Wolfner MF. Reproductionimmunity trade-offs in insects. Annual Review of Entomology 2016;61:239-56.

44. Shu Y, Du Y, Wang J. Molecular characterization and expression patterns of Spodoptera litura heat shock protein 70/90, and their response to zinc stress. Comparative Biochemistry and Physiology Part A: Molecular \& Integrative Physiology 2011;158:102-10.

45. Shukla JN, Kalsi M, Sethi A, Narva KE, Fishilevich E, Singh $\mathrm{S}$ et al. Reduced stability and intracellular transport of dsRNA contribute to poor RNAi response in lepidopteran insects. RNA Biology 2016;13(7):656-669.

46. Singh IK, Singh S, Mogilicherla K, Shukla JN, Palli SR. 
Comparative analysis of double-stranded RNA degradation and processing in insects. Scientific Reports 2017;7:17059.

47. Sun XQ, Zhang MX, Yu JY, Jin Y, Ling B, Du JP et al. Glutathione $\mathrm{S}$-transferase of brown planthoppers (Nilaparvata lugens) is essential for their adaptation to gramine-containing host plants. PLoS One. 2013;8:e64026.

48. Terenius O, Papanicolaou A, Garbutt JS, Eleftherianos I, Huvenne H, Kanginakudru S et al. RNA interference in Lepidoptera: an overview of successful and unsuccessful studies and implications for experimental design. Journal of Insect Physiology 2011;57:231-245.

49. Toprak U, Baldwin D, Erlandson M, Gillott C, Harris S, Hegedus DD In vitro and in vivo application of RNA interference for targeting genes involved in peritrophic matrix synthesis in a lepidopteran system. Insect Science. 2013;20:92-100.

50. Ulvila J, Parikka M, Kleino A, Sormunen R, Ezekowitz RA, Kocks C et al. Double-stranded RNA is internalized by scavenger receptor-mediated endocytosis in Drosophila S2 cells. Journal of Biological Chemistry. 2006;281:14370-5.

51. Vogel E, Santos D, Mingels L, Verdonckt TW, Broeck JV. RNA interference in insects: protecting beneficials and controlling pests. Frontiers in Physiology. 2019;9:1912. doi: 10.3389/fphys.2018.01912.

52. Wang K, Peng Y, Pu J, Fu W, Wang J, Han Z. Variation in RNAi efficacy among insect species is attributable to dsRNA degradation in vivo. Insect Biochemistry and Molecular Biology 2016;77:1-9.

53. Wilson RC, Doudna JA. Molecular mechanisms of RNA interference. Annual Review of Biophysics 2013;42:217239.

54. Wynant N, Santos D, Van Wielendaele P, VandenBroeck J. Scavenger receptor-mediated endocytosis facilitates RNA interference in the desert locust, Schistocerca gregaria. Insect Molecular Biology 2014;23:320-9.

55. Yoon JS, Mogilicherla K, Gurusamy D, Chen X, Chereddy SC, Palli SR. Double-stranded RNA binding protein, Staufen, is required for the initiation of RNAi in coleopteran insects. Proceedings of the National Academy of Sciences 2018;115(33):8334-8339.

56. Yu XD, Liu ZC, Huang SL, Chen ZQ, Sun YW, Duan PF et al. RNAi-mediated plant protection against aphids. Pest Management Science 2016;72(6):1090-1098.

57. Zhang H, Li HC, Miao XX. Feasibility, limitation and possible solutions of RNAi-based technology for insect pest control. Insect Science 2013;20:15-30.

58. Zhang J, Khan SA, Heckel DG, Bock R. Next-generation insect-resistant plants: RNAi-mediated crop protection. Trends in Biotechnology 2017;35(9):871-882.

59. Zhou X, Wheeler MM, Oi FM, Scharf ME. RNA interference in the termite Reticulitermes flavipes through ingestion of double-stranded RNA. Insect Biochemistry and Molecular Biology 2008;38(8):805-815.

60. Zhu F, Xu J, Palli R, Ferguson J, Palli SR. Ingested RNA interference for managing the populations of the Colorado potato beetle, Leptinotarsa decemlineata. Pest Management Science 2011;67:175-82.

61. Zotti M, dos Santos EA, Cagliari D, Christiaens O, Taning CN, Smagghe G. RNA interference technology in crop protection against arthropod pests, pathogens and nematodes. Pest Management Science 2018;74:1239-50. 